\title{
COMPORTAMENTO ANTE A CRISE DA VARIABLE EMPREGO NO SECTOR TURÍSTICO: ANÁLISE
} COMPARATIVA ENTRE ESPAÑA E FRANCIA

Mercedes Jiménez García, mercedes.jimenezgarcia@uca.es Antonio Rafael Peña Sánchez, rafael.pena@uca.es José Ruiz Chico, jose.ruizchico@uca.es

Facultade de Ciencias Sociais e da Comunicación, Departamento de Economía Xeral, Universidade de Cádiz

RESUMO. Este traballo céntrase en analizar como a crise económica afectou ao emprego turístico en Francia e España, dúas das principais potencias turísticas, e se esta variable presentou un comportamento semellante tanto antes como durante a crise. Os principais resultados amosan a maior influencia na xeración de emprego turístico pola chegada de turistas estranxeiros en España, fronte ao nivel de riqueza no caso francés; a diverxencia no emprego turístico rexional durante a crise en España mentres que en Francia continuou a converxencia rexional de anos anteriores; e, finalmente, as variacións nos compoñentes do crecemento do emprego nas principais rexións turísticas, Cataluña e Îlede-France, durante a crise.

Palabras chave: turismo; emprego; converxencia; shift-share.

BEHAVIOR OVER THE EMPLOYMENT CRISIS OF VARIABLE IN THE TOURISM SECTOR: A COMPARATIVE ANALYSIS BETWEEN SPAIN AND FRANCE

ABSTRACT.This paper focuses on analyzing how the economic crisis has affected the tourism employment in France and Spain, two of the main tourist powers, and if this variable has presented a similar behavior before and during the crisis. The main results show the greatest influence on the generation of tourism employment of foreign tourist arrivals in Spain, compared to the level of wealth, in the French case; divergence in regional tourism employment during the crisis in Spain and in France has continued regional convergence in past years; and finally, variations in the components of employment growth in major tourist regions, Catalonia and the Île-de-France, during the crisis.

Keywords: tourism; employment; convergence; shift-share.

Clasificación JEL: L83, N34.

\section{INTRODUCIÓN.}

A crise económica actual que ven atravesando numerosos países fai propicia a investigación do comportamento dos distintos sectores baixo estas condicións socioeconómicas diferentes e particularmente difíciles. Neste senso, resulta interesante 0 estudo do sector turístico, xa que diversa literatura ao respecto fai referencia a un comportamento diferente durante etapas de recesión e crise do ciclo económico, en canto á tendencia estable e superación destes períodos (Torres, 1994; Massieu, 2004; Flores e Barroso, 2010).

A industria do turismo é, na actualidade, un sector que se configura como motor da economía de moitos países, sobre todo os desenvolvidos e emerxentes (Nel-lo e Pérez, 2007; Moreno e Picazo, 2012). A nivel mundial, o turismo representa o 9\% do PIB e o 8\% do emprego total (Ministère de l'écologie, du développement durable et de l'énergie, 2012), e a pesar da situación de crise económico-financeira na que se atopan inmersas a meirande parte das economías, nos primeiros oitos meses de 2013 as chegadas de turistas internacionais aumentaron un 5\%, situando os resultados do turismo internacional por enriba da media do crecemento económico na maioría das rexións mundiais (OMT, 2013a). 
Seguindo a clasificación da Organización Mundial de Turismo (OMT), Europa é a primeira rexión turística a nivel mundial, tanto por chegadas como por ingresos de turismo internacional (cunha cota de mercado superior ao $50 \%$ e ao $40 \%$, respectivamente) (OMT, 2013b).

Asemade, en Europa, os países máis destacados turisticamente son Francia e España, que ocupan a primeira e cuarta posición do ránking da OMT sobre os principais destinos turísticos do mundo por chegadas de turistas internacionais (con 83 e 58 millóns de visitantes, respectivamente), e sitúanse no terceiro e segundo posto en canto a ingresos por turismo internacional (54.000 e 56.000 millóns de dólares, respectivamente) (OMT, 2013b).

O turismo, por tanto, preséntase como un sector fundamental para as economías francesa e española, tanto en canto a emprego como contribución ao PIB ${ }^{1}$. É por iso polo que este traballo se centra na análise comparativa destes dous países.

En base á formulación anterior, xorden unha serie de interrogantes relacionados co comportamento do sector turístico en Francia e España antes e durante a actual época de crise: responde da mesma maneira o sector turístico ante a crise actual en Francia e en España? A resposta do sector turístico aumenta a diverxencia entre as rexións destes países? Cales son os compoñentes do crecemento do emprego neste sector nas principais rexións turísticas dos países analizados, a saber, Île-de-France e Cataluña²?

A todas estas cuestións trataremos de responder ao longo deste traballo, tomando como variable central das diversas análises o emprego no sector turístico.

Para tal fin, as fontes estatísticas consultadas foron: a Organización Mundial de Turismo (OMT), o Ministère de l'écologie, du Développement durable et de l'énergie, a base de datos de EUROSTAT, o Instituto Nacional de Estatística (INE), o Instituto de Estudos Turísticos (IET), o Ministerio de Industria, Enerxía e Turismo, a Direction Générale de la Compétitivité de l'industrie et des Services (DGCIS) e o Institut National de la Statistique et des Études Économiques (INSEE).

O trabajo estrutúrase do seguinte xeito: no segundo apartado analízase a posible existencia dun comportamento semellante do emprego turístico en España e Francia perante a situación de crise actual; no terceiro apartado valórase se a crise contribuíu ao incremento ou redución da converxencia rexional no emprego do sector turístico nos dous países; no cuarto apartado examínanse os compoñentes de crecemento do emprego en turismo nas principais rexións turísticas das economías analizadas: Cataluña e Île-deFrance; e no epígrafe final reúnense as principais ideas e conclusións da análise efectuada.

1 En Francia, a industria do turismo representa o 6,5\% do seu PIB (Ministère de l'écologie, du développement durable et de l'énergie, 2012) e os traballadores en aloxamento e restauración o $3,8 \%$ da súa poboación activa (INSEE, 2010). Para o caso español, o turismo supón o 15,2\% do PIB (WTTC, 2013) e os ocupados en hostalería representaban en 2012 o 7,2\% do total da población activa en España (INE).

2 Cataluña representa o primeiro destino turístico en España, recibindo en 2011, un total de 13,8 millóns de chegadas de turistas internacionais (o que representa o $24 \%$ das chegadas turísticas a España) (IET, 2012:106). Por outra banda, en Francia, destaca a rexión de Île-de-France como a principal receptora de chegadas de turismo internacional, aumentando en 2012 estas chegadas nun $3,2 \%$ con respecto ao ano precedente (INSEE). Ademais, según o Global Destination Cities Index 2013, entre o top ten das cidades máis visitadas do mundo atópanse, en terceiro lugar, París, e en décimo posto, Barcelona. 


\section{RESPOSTA DO SECTOR TURÍSTICO PERANTE A CRISE ENESPAÑa E FRANCIA.}

Co fin de realizar un achegamento inicial ao primeiro interrogante formulado neste traballo, e dada a importancia do turismo en termos de emprego e tamén pola súa contribución ao PIB de España e Francia, xa comentada no epígrafe precedente, realízase unha comparativa entre a taxa de crecemento das súas economías, medida a través do PIB, e a dos ocupados no sector turístico, co fin de analizar o seu comportamento (Gráfico 1).

GRÁFICO 1: EVOLUCIÓN DO CRECEMENTO DO PIB E DOS OCUPADOS EN TURISMO, EN FRANCIA E EN ESPAÑA (ENPORCENTAXE).

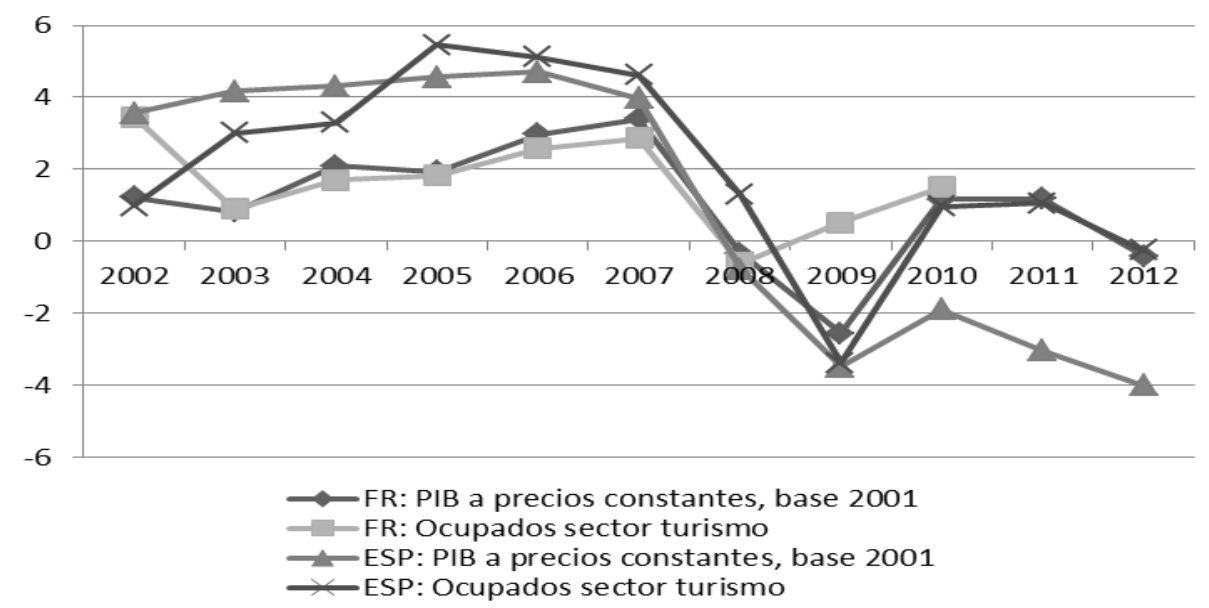

Notas: o último dato dispoñible de emprego por sector de actividade para Francia corresponde ao ano 2010. As series de PIB para o período estudado atópanse valoradas a prezos correntes polo que a partir da serie de Índice de Prezos ao Consumo (IPC) (INE, INSEE), calculáronse as series do PIB a prezos constantes, realizando un cambio de base para o ano 2001 para presentar unha información homoxénea nos dous países. Fonte: Elaboración propia a partir do INSEE, INE e o Ministerio de industria, enerxía e turismo.

No Gráfico 1 obsérvase, a través da evolución da taxa de crecemento do PIB, a chegada da crise en 2008 a Francia e España, cunha recrudescencia da mesma en 2009, chegando incluso a amosar taxas negativas para 2012.

En canto aos ocupados no sector turístico, en 2008 hai un descenso maior en Francia, aínda que a partir daí presenta unha progresión crecente da súa taxa de crecemento, incluso en 2009, o ano de maior caída no PIB. En España, o maior descenso no crecemento dos ocupados en turismo coincide co ano 2009, e aínda que amosa unha lixeira recuperación en 2010 e 2011, volve presentar valores negativos en 2012.

Por tanto, dende o comezo da crise foi comprobado un mellor comportamento nas taxas de crecemento dos ocupados en turismo por enriba do crecemento do PIB das economías francesa e española. Ademais, o sector turístico presenta mostras de recuperación da súa actividade malia o comportamento do PIB, para o caso do país galo, e incluso perante un peor comportamento interanual desta macromagnitude no caso español.

Estas observación parecen non só reforzar a formulación dun comportamento máis estable e recuperación anticipada do sector turístico perante un período económico desfavorable, senón que apunta á existencia dunha resposta diferente deste sector ante a crise en Francia e España. 
Para profundar neste aspecto, emprégase a análise de regresión na que se representa a relación existente entre os empregos do sector turístico (ET) co nivel de riqueza xerada na economía (PIB) e coa chegada de turistas (TUR) da seguinte forma:

$$
\mathrm{ET}_{\mathrm{it}}=\mathrm{F}\left(\mathrm{PIB}_{\mathrm{it}}, \mathrm{TUR}_{\mathrm{it}}\right)
$$

Todas estas variables veñen referidas á rexión i-ésima no período " $\mathrm{t}$ ". A ecuación anterior pódese representar nos seguintes termos:

$$
\log \left(\mathrm{ET}_{\mathrm{it}}\right)=\mathrm{C}_{\mathrm{it}}+\alpha \log \left(\mathrm{PIB}_{\mathrm{it}}\right)+\beta \log \left(\mathrm{TUR}_{\mathrm{it}}\right)
$$

Os resultados da ecuación [2] estímanse empregando mínimos cadrados ordinarios (MCO) (que equivale á estimación do modelo de efectos fixos de datos en panel), e cuxos resultados se reflicten no seguinte cadro: ${ }^{3}$

CADRO 1: FACTORES EXPLICATIVOS DOS EMPREGOSTURÍSTICOS DAS REXIÓNSESPAÑOLASE FRANCESAS.

\begin{tabular}{|l|c|c|c|c|}
\hline \multirow{2}{*}{ Estimacións } & \multicolumn{2}{|c|}{ España } & \multicolumn{2}{c|}{ Francia } \\
\cline { 2 - 5 } & Coeficiente & t-estatístico & Coeficiente & t-estatístico \\
\hline $\mathrm{C}_{\mathrm{it}}$ & 3,671293 & 9,444904 & $-1,410266$ & $-10,09724$ \\
\hline $\log \left(\mathrm{PIB}_{\mathrm{it}}\right)$ & 0,050233 & 2,606181 & 0,855338 & 36,93685 \\
\hline $\log \left(\mathrm{TUR}_{\mathrm{it}}\right)$ & 0,482428 & 23,808770 & 0,167779 & 10,20000 \\
\hline $\mathrm{R}^{2}$ & \multicolumn{2}{|c|}{0,801315} & 0,972611 \\
\hline $\mathrm{R}^{2}$ axustado & 0,799267 & 0,972330 \\
\hline Test de Durbin-Watson & \multicolumn{2}{|c|}{1,714462} & 1,944988 \\
\hline Test F & 391,2105 & $3.462,330$ \\
\hline $\mathrm{n}$ - observacións & 204 & \multicolumn{2}{|c|}{198} \\
\hline (Modelos de regresión MCO - Datos de panel) \\
Variable dependente: $\log ($ ETit)
\end{tabular}

Fonte: Elaboración propia.

As regresións realizadas a partir de datos en panel superaron os test aplicados sobre autocorrelación e multicolinearidade, y foron corrixidos de heterocedasticidade mediante o procedemento de White. Contrastadas o resto das hipóteses do modelo, pódese afirmar que todos os coeficientes dos factores produtivos considerados son altamente significativos, e presentan os signos esperados. Os modelos son explicativos, como queda demostrado tanto polo coeficiente de determinación ( $\mathrm{R}^{2}$ e $\mathrm{R}^{2}$ axustado) como polo test $\mathrm{F}$ de Snedecor.

Nos dous modelos formulados, a participación no emprego turístico da riqueza xerada e da chegada de turistas presentan coeficientes positivos e altamente significativos, polo que se estima que estas dúas últimas variables xogaron un papel importante na xeración de emprego no sector turístico dos dous países. Por tanto, os resultados anteriores confirman a importancia da capacidade produtiva xeral da economía e da chegada de turistas na xeración de emprego no sector turístico de cada un dos países estudados. Porén, existen diferencias en canto á aportación que realiza cada unha das variables

3 Tanto a análise de regresión como a posterior análise de converxencia realízanse con datos do período 2001-2012 para España e 2003-2011 para Francia. O motivo desta lixeira disimilitude responde á súa dispoñibilidade nas diferentes bases de datos consultadas. Porén, considérase que 0 modelo é estable e non afecta aos resultados da investigación de forma significativa, ao existir un número suficientemente importante de datos para realizar as estimacións, sen que se reste validez á análise efectuada. Dende o punto de vista territorial, efectuaronse as análises para as 17 Comunidades Autónomas españolas e as 22 rexións francesas pertencentes á Francia Metropolitana. 
consideradas como independentes no modelo. Co fin de confirmar estas diferenzas, estableceuse a mesma estimación anterior coas variables estandarizadas ${ }^{4}$. Os resultados obtidos preséntanse a continuación (Cadro 2):

CADRO 2: FACTORES EXPLICATIVOS DOS EMPREGOS TURÍSTICOS DAS REXIÓNS ESPAÑOLAS E FRANCESAS (DATOSESTANDARIZADOS).

\begin{tabular}{|l|c|c|c|c|}
\hline \multirow{2}{*}{ Estimacións } & \multicolumn{2}{|c|}{ España } & \multicolumn{2}{c|}{ Francia } \\
\cline { 2 - 5 } & Coeficiente & t-estatístico & Coeficiente & t-estatístico \\
\hline $\mathrm{PIB}_{\text {it }}$ & 0,115866 & 1,925614 & 0,842725 & 32,01659 \\
\hline $\mathrm{TUR}_{\mathrm{it}}$ & 0,770941 & 14,37232 & 0,132465 & 5,095593 \\
\hline $\mathrm{Ar}(1)$ & 0,146773 & 2,696093 & 0,519881 & 7,045220 \\
\hline $\mathrm{Ar}(2)$ & - & - & $-0,210019$ & $-2,796851$ \\
\hline $\mathrm{R}^{2}$ & \multicolumn{2}{|c|}{0,579986} & 0,986976 \\
\hline $\mathrm{R}^{2}$ axustado & \multicolumn{2}{|c|}{0,575634} & 0,986773 \\
\hline Test de Durbin-Watson & \multicolumn{2}{|c|}{1,983929} & \multicolumn{2}{c|}{1,983579} \\
\hline Test F & \multicolumn{2}{|c|}{133,2544} & \multicolumn{2}{c|}{1950,113} \\
\hline $\mathrm{n}$ - observacións & \multicolumn{3}{|c|}{ 204 } & \multicolumn{2}{|c|}{} \\
\hline (Modelos de regresión MCO - Datos de panel). Variable dependente: ETit \\
\hline
\end{tabular}

Fonte: Elaboración propia.

Conforme os resultados que se desprenden do cadro anterior, os datos presentan de novo os sinais esperados, e ao seren datos estandarizados permiten a comparación dos coeficientes estimados 5 . Obsérvase como no caso español, que a chegada de turistas presenta un coeficiente maior co do francés; porén, o coeficiente da xeración de riqueza (que presenta un nivel de confianza do 90\%), é destacadamente menor ao que presenta a regresión das rexións francesas. Polo anterior, e segundo os resultados obtidos pola estimación realizada e as fontes estatísticas utilizadas, constátase como para os dous países analizados a xeración de riqueza e as visitas turísticas presentan unha destacada influencia no emprego do sector turístico, aínda que a aportación das dúas é distinta en cada caso.

\section{AS DISPARIDADES REXIONAIS EN ESPAÑA E FRANCIA DENDE A ÓPTICA TURÍSTICA.}

Unha vez coñecida a influencia das variables chegadas de turistas estranxeiros e PIB sobre o emprego turístico en Francia e España, a seguinte cuestión obxecto de análise é coñecer se a resposta do sector turístico, en termos de emprego, durante a crise aumenta a diverxencia entre as rexións destes países. Para iso realízase unha análise de converxencia sigma dos traballadores en turismo con respecto ao total de empregos sectoriais.

A convergencia sigma ( $\sigma$ ) é unha medida de dispersión que indica o grao de desigualdade existente entre as distintas economías, tomando como referencia unha determinada variable económica. Establécese que entre un grupo de entes territoriais existe unha tendencia á converxencia se a dispersión da variable económica en cuestión entre eles tende a reducirse no tempo (Martín, 1998:132). Esta dispersión adoita medirse mediante a desviación estándar da mostra, ou ben mediante o coeficiente de variación. Cando a devandita dispersión amosa unha tendencia a reducirse no período analizado afírmase

4 As variables estandarizáronse estatisticamente mediante a expresión: sendo " $\mathrm{XN}$ " o dato normalizado, " $\mathrm{x}$ " o dato orixinal, o valor medio da variable analizada, "S" a desviación típica da variable, e "i" cada unha das rexións.

${ }^{5}$ Ao estandarizar todas as variables que se aplican ao modelo, están sendo expresadas cunha mesma base e, como consecuencia, pódense comparar de forma directa. Véxase ao respecto Gujarati (2004). 
que se está a producir unha converxencia sigma. Por tanto, e resumindo o anterior, pódese definir como a evolución no tempo das desviacións estándar do logaritmo da variable elixida (neste caso, o emprego en turismo). A fórmula utilizada é a seguinte:

$$
\sigma_{t}=\sqrt{\frac{\sum_{i=1}^{N}\left(\ln E T_{i t}-\ln E T_{t}\right)^{2}}{N}}
$$

onde "InET it" é o logaritmo do emprego no sector turístico en relación á poboación ocupada da área xeográfica " $\mathrm{i}$ " no ano " $\mathrm{t}$ ", " $\mathrm{nET}_{\mathrm{t}}$ " é o logaritmo do emprego no sector turístico en relación á poboación ocupada da economía rexional no ano " $\mathrm{t}$ ", e " $\mathrm{N}$ " se corresponde ao número de espazos territoriais que compoñen a economía nacional.

Tras a aplicación da converxencia sigma a nivel rexional, no Gráfico 2 obsérvase un comportamento diferente entre España e Francia no emprego turístico durante o período de crise. A desaceleración económica provocou entre 2007 e 2012 un forte proceso diverxente en España, mentres que en Francia mantívose a mesma liña de converxencia que en anos anteriores. É dicir, en España, os traballadores por turismo concéntranse máis nalgunhas rexións ca noutras.

GRÁFICO 2: CONVERXENCIA SIGMA DOS EMPREGOS ENTURISMO EN ESPAÑA E FRANCIA, 2001-2012.

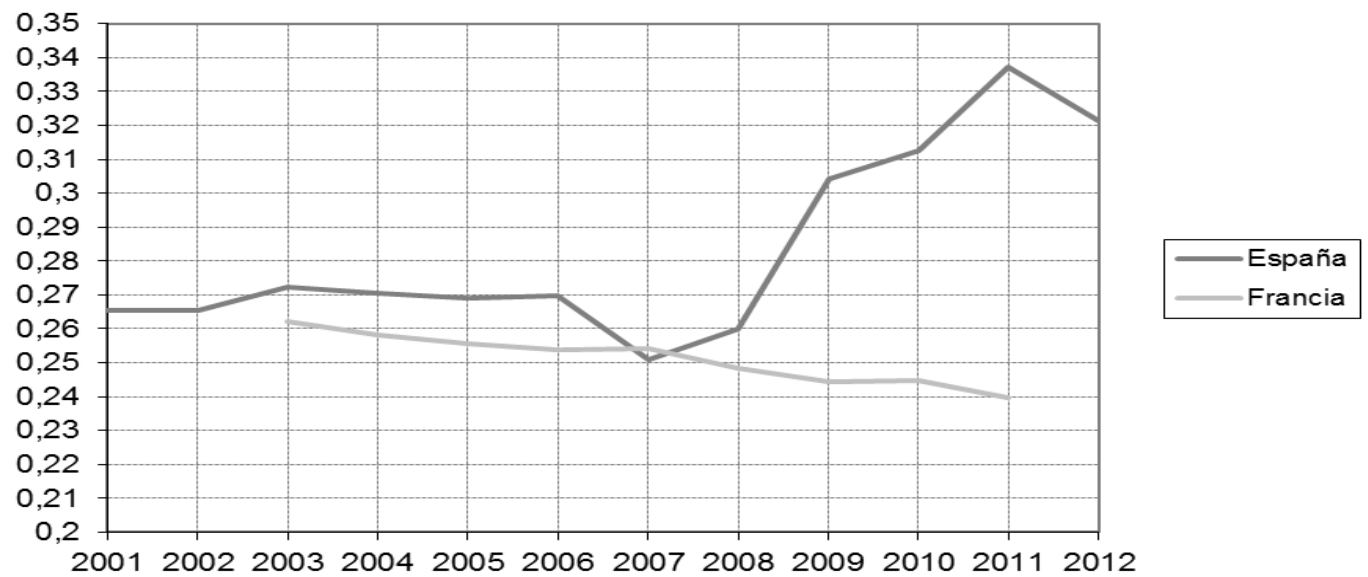

Fonte: Elaboración propia.

En termos netos de emprego, prodúcese en España un crecemento do mesmo entre 2001 e 2012, aínda que se observa o efecto da crise en canto á destrución de emprego turístico entre 2007 e 2012. Algunhas rexións experimentaron unha destrución de emprego máis intensa ca outras polo que o proceso de diverxencia rexional observado durante a crise vén provocado pola destrución máis intensa de emprego nalgunhas rexións e non pola súa creación.

En Francia, en termos xerais, produciuse creación de emprego en turismo durante o período de crise nas diferentes rexións, namentres que na variable empregos totais, se observa unha destrución de emprego xeralizada. 
Por tanto, pódese dicir que, en España, a destrución de emprego xeral estivo acompañada pola destrución de emprego en turismo, namentres que en Francia, foi contrarrestada pola xeración de emprego turístico en 2007-2011, provocando que observara diverxencia rexional no primeiro caso, e unha lixeira converxencia no segundo, no período analizado, con respecto ao emprego turístico.

\section{ANÁLiSE dos COMPOÑENTES do CRECEMENTO do EMPREgo TURÍSTICO EN CATALUÑa E ÎLE-DE- FRANCE.}

Descendendo o nivel de análise do ámbito nacional ao rexional, aplícase a continuación unha análise shift-share dinámica espacialmente modificada para coñecer os compoñentes do crecemento do emprego en turismo nas principais rexións turísticas dos países analizados, Cataluña e Île-de-France ${ }^{6}$, co obxecto de coñecer tamén se existen diferenzas neste aspecto en territorios máis específicos ou se observan semellanzas entre os dous.

A análise shift-share é unha das ferramentas máis empregadas en economía rexional para medir os compoñentes do crecemento económico de determinadas áreas xeográficas, subdivíndoas en tres efectos (nacional, sectorial ou estrutural e rexional ou competitivo) (Dunn, 1960). Porén, a formulación clásica do shift-share viuse sometida a diversas revisións e extensións en resposta ás limitacións deste modelo (Casler, 1989; Chalmers e Beckhelm, 1976; Gerking e Barrington, 1981; Knudsen e Barf, 1991), entre as que se atopan a ausencia da consideración das relacións interrexionais. Neste senso, recentemente xurdiron novas aportacións á análise tradicional, denominándose o shiftshare espacial (Nazara e Hewings, 2004; Mayor e López, 2005; Ramajo e Márquez, 2008).

Nesta investigación pártese do shift-share espacialmente modificado proposto por Ramajo e Márquez (2008) - xa que, a diferenza dos modelos de Nazara e Hewings, (2004) e Mayor e López (2005), conserva os efectos tradicionais, aos que engade as interaccións espaciais, ao que se lle aplicou unha construción dinámica, co obxecto de estudar a evolución dos seus efectos ao longo do período de análise temporal.

Dado que a proposta de shift-share espacial de Ramajo e Márquez (2008) parte da súa formulación clásica, convén sinalar que vén expresada pola seguinte identidade:

$$
E_{i j}^{\prime \prime}-E_{i j}=\Delta E_{i j}=E_{i j} r+E_{i j}\left(r_{i}-r\right)+E_{i j}\left(r_{i j}-r_{i}\right)
$$

onde,

$E_{i j}^{\prime}$ : valor da variable emprego no período final, correspondente ao sector $\mathrm{i}(\mathrm{i}=1, \ldots, \mathrm{S})$ no ámbito espacial $\mathrm{j}(\mathrm{j}=1, \ldots, \mathrm{R})$.

$E_{i j}$ : valor do emprego no período inicial, correspondente ao sector $\mathrm{i}(\mathrm{i}=1, \ldots, \mathrm{S})$ no ámbito espacial $\mathrm{j}(\mathrm{j}=1, \ldots, \mathrm{R})$.

$$
r=\frac{\sum_{i=1}^{S} \sum_{j=1}^{R}\left(E_{i j}^{i}-E_{i j}\right)}{\sum_{i=1}^{S} \sum_{j=1}^{R} E_{i j}}
$$

$$
r_{i}=\frac{\sum_{i=1}^{R}\left(E_{i j}^{i}-E_{i j}\right)}{\sum_{j=i}^{R} E_{i j}}
$$$$
\tilde{\gamma}_{i j}=\frac{E_{i j}^{\prime}-E_{i j}}{E_{i j}}
$$

6 Para a realización desta análise identificáronse como rexións veciñas de Cataluña a Aragón, Valencia, Midi-Pyrénées e Languedoc-Roussillon. E como rexións veciñas de Île-de-France, as seguintes: Picardie, Haute-Normandie, Centre, Bourgogne e Champagne-Ardenne. 
Desprendéndose da expresión [5] os tres efectos da análise shift-share clásica: efecto nacional $\left(E_{i j} r\right)$, efecto sectorial ou estrutural $\left(E_{i j}\left(r_{i}-r\right)\right)$ e efecto rexional ou competitivo $\left(E_{i j}\left(r_{i j}-r_{i}\right)\right)$, tamén coñecidos de agora en adiante polas súas respectivas siglas, como EN, ES e ER.

A proposta de Ramajo e Márquez (2008) consiste en engadir a esta análise tradicional o seguinte desenvolvemento de shift-share espacial:

$$
E_{i j}^{\prime}-E_{i j}=\Delta E_{i j}=W\left(E_{i j} r\right)+\left[W E_{i j} *\left(r_{i}-r\right)\right]+\left[E_{i j} r_{i j}-W\left(E_{i j} r_{i}\right)\right]
$$

A partir da expresión anterior [6] obsérvase a aparición de novos efectos espaciais: o efecto nacional local $\left(W\left(E_{i j} r\right)\right)$, denominado de agora en adiante ENL, equivalente ao efecto nacional tradicional pero a nivel local. Neste caso, en lugar de empregar a taxa de crecemento nacional, utilízase o crecemento medio dos sectores nas rexións veciñas para comparar o crecemento da rexión. O efecto sectorial locacional (ESL), recollido polo termo $\left[W E_{i j} *\left(r_{i}-r\right)\right]$ expresa a vantaxe competitiva da rexión no sector i con respecto ás rexións veciñas, e o efecto rexional locacional (ERL), expresado como $\left[E_{i j} r_{i j}-W\left(E_{i j} r_{i}\right)\right]$, mide o grao de especialización sectorial de cada rexión, identificando se se atopa especializada nas ramas nas que ten vantaxe competitiva con respecto ás rexións veciñas (Ramajo e Márquez, 2008; Arias e Sánchez, 2010).

Porén, antes de someter o territorio obxecto de estudo a unha análise shift-share dinámica espacialmente modificada, é preciso detectar a presenza de autocorrelación espacial para a variable estudada (no noso caso, o emprego no sector turístico) (Arias e Sánchez, 2010:14). Para iso, nesta investigación empregouse 0 índice da I de Moran, ${ }^{7}$ cuxa expresión matemática é a seguinte:

$$
I=\frac{n}{S_{0}} \frac{\sum_{j=1}^{n} \sum_{k=1}^{n} w_{j k} z_{j} z_{k}}{\sum_{j=1}^{n} z_{j}^{2}} ; j \neq k
$$

onde, $z_{j}=x_{j}-\bar{x}^{\mathrm{y}} S_{0}=\sum_{j=1}^{n} \sum_{k=1}^{n} w_{j k}$

Sendo n o número de casos, $x_{j}$ o valor da variable nun lugar determinado, $x_{k}$ o valor da variable noutro lugar diferente, $\bar{x}$ a media da variable $\mathrm{e}_{w_{j k}} \mathrm{o}$ peso aplicado á comparación entre a localización j e a localización k.

\footnotetext{
${ }^{7}$ A I de Moran require a construción previa da matriz de pesos espaciais W, matriz cadrada non estocástica cuxos elementos miden a interdependencia entre unidades territoriais a través de criterios de contigüidade en función dunha distancia baseada ben sexa nas relación comerciais entre elas, a lonxitude da fronteira común, a renda per cápita, os niveis de emprego, etc. No caso concreto que nos ocupa, empregouse o VABpc. A matriz de pesos estandarízase, acotando os pesos entre 0 e 1 , de forma que na diagonal principal todos os seus elementos son iguais a cero; os compoñentes de cada fila suman un e o valor dunha variable nun territorio é igual á súa media ponderada nas zonas veciñas .
} 
TÁBOA 1: TEST DE AUTOCORRELACIÓN ESPACIAL (2002-2012)

\begin{tabular}{|c|c|c|}
\hline & ESPAÑA & FRANCIA \\
\hline & I de Moran & I de Moran \\
\hline 2002 & $-0,155$ & 0,145 \\
\hline 2003 & $-0,291$ & 0,163 \\
\hline 2004 & $-0,330$ & 0,128 \\
\hline 2005 & $-0,338$ & 0,134 \\
\hline 2006 & $-0,351$ & 0,137 \\
\hline 2007 & $-0,491$ & 0,142 \\
\hline 2008 & $-0,595$ & 0,146 \\
\hline 2009 & $-0,503$ & 0,158 \\
\hline 2010 & $-0,505$ & 0,154 \\
\hline 2011 & $-0,530$ & 0,162 \\
\hline 2012 & $-0,499$ & 0,166 \\
\hline $2002-2012$ & $\mathrm{Z}(\mathrm{i})=2,11$ & $\mathrm{Z}(\mathrm{i})=1,69$ \\
\cline { 2 - 3 } & $\mathrm{p}$-valor $=0,0348$ & $\mathrm{p}$-valor $=0,091$ \\
\hline
\end{tabular}

Nota: Para o cálculo das matrices de pesos espaciais empregouse o VABpc. No caso das rexións francesas só se dispón de información desta variable ata o ano 2011, polo que se empregou 0 método de predición Naïve II, cun coeficiente de alisamento de 0,8 , para estimar os valores da serie en 2012. O mesmo método empregouse para obter a cifra de emprego en turismo para Francia en 2012, necesaria para calcular a relevancia estatística. Fonte: Elaboración propia.

A I de Moran amosa, a partir da Táboa 1, a presenza de asociación entre valores similares, para o caso de Francia, e disímiles, para el caso de España, durante todos os anos que compoñen o período de estudo ( $\mathrm{I}>0, \mathrm{I} \varangle 0$, respectivamente). Esta correlación espacial é maior para España, que presenta valores máis achegados a -1, e vaise incrementando dun año ao seguinte. Rexéitase a hipótese nula nos dous casos, a un nivel de significación do 5\% para España e do 10\% para Francia.

Seguindo a metodoloxía de Ramajo e Márquez (2008:265), aplícase o shift-share espacialmente modificado cun enfoque dinámico, obténdose os diferentes efectos da análise realizada para cada ano do período de estudo (2002-2012) (Táboas 2 e 3).8

De forma xeral, para o período de estudo 2002-2012, na primeira parte do shift-share espacial, correspondente á análise clásica, obsérvase como nos dous territorios estudados existe un crecemento maior dos ocupados en turismo con respecto á media do resto de rexións dos respectivos países polo bo comportamento da variable a nivel nacional (efecto sectorial) que, no caso de île-de-France tamén vén explicado polo dinamismo do sector na rexión en comparación co sector a nivel nacional. En canto aos últimos tres compoñentes da análise, que inclúen o efecto locacional, aínda se observa un efecto neto positivo nos dous casos (ESL+ERL), motivado tanto por factores estruturais a nivel local como por un crecemento medio dos ocupados en turismo de Cataluña e Île-de-France superior ao das rexións contiguas, o que se traduce nunha maior competitividade. Isto pode motivar a posibilidade de falar destos destinos como clústers turísticos xa sexa dende a óptica de

8 A serie de datos orixinal vén expresada de forma trimestral. Porén, seguindo a Barf e Knight (1988), usáronse datos anuais para a formulación dinámica do shift-share, aínda que existen aplicación dinámicas con outros períodos temporais. Véxase ao respecto a Garrido (2002:115). 
clúster como produto turístico ou dende o punto de vista da aplicación da teoría de Porter e o seu modelo de competitividade (véxase Varisco, 2007:34).

TÁBOA 2: SHIFT-SHARE ESPACIAL E ESPACIAL DINÁMICO PARA OS OCUPADOS EN TURISMO EN CATALUÑA (2002-2012)

\begin{tabular}{|c|c|c|c|c|c|c|}
\hline \multicolumn{7}{|c|}{ Cataluña: Shift-share espacial (2002-2012) } \\
\hline & EN & $\mathrm{ES}$ & ER & ENL & ESL & ERL \\
\hline & 85980,70 & 451500,17 & $-17558,87$ & 16040,83 & 84233,29 & 419647,89 \\
\hline \multicolumn{7}{|c|}{ Cataluña: Shift-share espacial dinámico (2002-2012) } \\
\hline & EN & $\mathrm{ES}$ & ER & ENL & ESL & ERL \\
\hline 2002 & 63490,23 & 31315,06 & $-18369,29$ & 11941,35 & 5889,79 & 61363,58 \\
\hline 2003 & 87824,60 & $-17007,60$ & $-27976,00$ & 16198,28 & $-3136,86$ & 29779,59 \\
\hline 2004 & 87293,08 & $-14766,76$ & $-10656,32$ & 15877,36 & $-2685,86$ & 48678,50 \\
\hline 2005 & 128234,59 & 12454,90 & $-41,49$ & 23169,43 & 2250,35 & 115228,22 \\
\hline 2006 & 99573,76 & 31642,75 & $-3058,51$ & 17590,97 & 5590,09 & 104976,94 \\
\hline 2007 & 79103,32 & 40526,11 & $-12214,43$ & 11670,81 & 5979,17 & 89765,02 \\
\hline 2008 & $-12928,45$ & 54147,51 & 12160,94 & $-1685,36$ & 7058,70 & 48006,66 \\
\hline 2009 & $-184482,79$ & 82450,42 & 10732,36 & $-28027,84$ & 12526,41 & $-75798,57$ \\
\hline 2010 & $-60241,99$ & 87684,45 & 6694,54 & $-9159,71$ & 13332,29 & 29964,41 \\
\hline 2011 & $-50934,15$ & 83199,88 & 7553,27 & $-7556,39$ & 12343,21 & 35032,18 \\
\hline 2012 & $-123194,40$ & 119308,51 & 6839,89 & $-19083,01$ & 18481,08 & 3555,93 \\
\hline \multicolumn{7}{|c|}{ Estatísticas descritivas } \\
\hline Media & 10339,80 & 46450,48 & $-2575,91$ & 2812,35 & 7057,12 & 44595,68 \\
\hline Mediana & 6349 & 40526,11 & $-41,49$ & 11670,81 & 5979,17 & 48006,66 \\
\hline Máx & 128234,59 & 119308,51 & 12160,94 & 23169,43 & 18481,08 & 115228,22 \\
\hline Mín & $-184482,79$ & $-17007,60$ & $-27976,00$ & $-28027,84$ & $-3136,86$ & $-75798,57$ \\
\hline Desv. Estándar & 103153,23 & 43735,47 & 13156,48 & 16870,39 & 6740,66 & 52620,03 \\
\hline Suma & 113737,80 & 510955,23 & $-28335,03$ & 30935,89 & 77628,36 & 490552,46 \\
\hline
\end{tabular}

Fonte: Elaboración propia.

TÁBOA 3: SHIFT-SHARE ESPACIAL E ESPACIAL DINÁMICO PARA OS OCUPADOS EN TURISMO:ÎLE-DE-FRANCE 2002-2012

\begin{tabular}{|c|c|c|c|c|c|c|}
\hline \multicolumn{7}{|c|}{ Île-de-France: Shift-share espacial (2002-2012) } \\
\hline & EN & $\mathrm{ES}$ & ER & $\overline{E N L}$ & ESL & ERL \\
\hline & 41720,95 & 93937,50 & 9880,55 & 2985,47 & 6721,98 & 135831,55 \\
\hline \multicolumn{7}{|c|}{ Île-de-France: Shift-share espacial dinámico (2002-2012) } \\
\hline & EN & $\mathrm{ES}$ & $\mathrm{ER}$ & ENL & ESL & ERL \\
\hline 2002 & 7765,96 & 20368,77 & 418,27 & 558,66 & 1465,26 & 26529,08 \\
\hline 2003 & $-1828,63$ & 17024,15 & 518,49 & $-131,66$ & 1225,71 & 14619,95 \\
\hline 2004 & 1503,34 & 11167,88 & 1132,78 & 107,88 & 801,44 & 12894,67 \\
\hline 2005 & 6435,02 & 9751,13 & $-466,15$ & 459,91 & 696,91 & 14563,18 \\
\hline 2006 & 11275,98 & 5273,04 & 145,98 & 806,73 & 377,25 & 15511,02 \\
\hline 2007 & 18097,26 & 3774,01 & 2492,73 & 1292,46 & 269,53 & 22802,01 \\
\hline 2008 & 2617,44 & 3329,98 & 95,58 & 184,90 & 235,23 & 5622,87 \\
\hline 2009 & $-19537,68$ & 11685,94 & $-561,26$ & $-1383,40$ & 827,44 & $-7857,04$ \\
\hline 2010 & 4137,53 & 15103,17 & $-76,70$ & 293,47 & 1071,24 & 17799,30 \\
\hline 2011 & 10184,71 & 13286,29 & 492,00 & 722,73 & 942,83 & 22297,44 \\
\hline 2012 & 11374,57 & 1258,00 & 5852,43 & 805,15 & 89,05 & 17590,80 \\
\hline \multicolumn{7}{|c|}{ Estatísticas descritivas } \\
\hline Media & 4729,59 & 10183,85 & 913,10 & 337,89 & 727,45 & 14761,21 \\
\hline Mediana & 6435,02 & 11167,88 & 418,27 & 459,91 & 801,44 & 15511,02 \\
\hline Máx & 18097,26 & 20368,77 & 5852,43 & 1292,46 & 1465,26 & 26529,08 \\
\hline Mín & $-19537,68$ & 1258,00 & $-561,26$ & $-1383,40$ & 89,05 & $-7857,04$ \\
\hline
\end{tabular}




\begin{tabular}{|l|r|r|r|r|r|r|}
\hline Desv. Estándar & 9770,99 & 6161,23 & 1839,32 & 694,45 & 442,24 & 9361,46 \\
\hline Suma & 52025,50 & 112022,36 & 10044,14 & 3716,83 & 8001,90 & 162373,27 \\
\hline
\end{tabular}

Fonte: Elaboración propia.

Baixando a un nivel de análise máis detallada, as estatísticas descritivas da análise dinámica denotan que esta nos proporciona unha información cun menor nesgo e máis aproximativa ás causas explicativas do comportamento dos ocupados no sector turístico nos dous territorios estudados antes e durante a actual situación de crise.

Deste xeito, obsérvase unha menor repercusión da crise nos compoñentes do crecemento da variable estudada no caso de Île-de-France ca en Cataluña. Namentres que o primeiro presenta, durante todos os anos que compoñen o período de estudo, unha especialización maior que a nivel nacional e que nas súas rexións limítrofes, nun sector cun crecemento por enriba da media (efecto sectorial positivo tanto no seu compoñente tradicional (ES) como espacial (ESL)), para o caso de Cataluña apréciase que antes da crise, a economía nacional así como das rexións veciñas, "tiraba" ou producía un efecto arrastre dos ocupados en turismo, efecto que se inverte a partir de 2008, onde tanto EN como ENL adquiren valores negativos para todos os anos

Por outra banda, tamén se observa claramente a influencia da crise no signo do ER. Os ocupados por turismo en Cataluña tiveron un peor comportamento que o crecemento medio desta variable a nivel nacional, porén, a partir da crise obsérvase un dinamismo por enriba da media. Nembargantes, a nivel local, agás para 2009, o crecemento desta variable sempre estivo por enriba do presentado polas rexións veciñas.

Por tanto, en Cataluña detectáronse, antes da entrada da crise, desvantaxes a nivel nacional (ER negativo), pero vantaxes con respecto ás rexións limítrofes (ERL positivo) mentres que a partir da actual crise, as desvantaxes nacionais convertéronse nunha mellora da competitividade con respecto á media da nación e en continuar como rexión máis competitiva en poboación ocupada en turismo, en relación coas que a rodean (agás para 2009). Esta observación pódese explicar ou ben pola existencia de determinados factores en Cataluña que, en época de crise, supoñan unha vantaxe en relación ao comportamiento da nación, ou ben por unha máis acusada perda de competitividade do resto de Comunidades españolas no que a ocupados turísticos se refire, ou á conxunción das destas dúas explicacións.

Tanto en Île-de-France como en Cataluña, de forma xeral, a configuración da estrutura de ocupados no sector turístico é máis favorable a nivel global que a nivel local, mentres que, agás para 2009, as dúas rexións foron máis competitivas na variable analizada, a nivel local que a nivel global.

En definitiva, obsérvase un comportamento "máis sólido", con cambios menos acusados pola situación de crise nos efectos sobre o comportamento dos ocupados en turismo en Île-de-France ca en Cataluña (no primero, non todos os valores mínimos son negativos, fundamentalmente grazas a factores estruturais, e os cambios de sinais nos compoñentes explicativos do comportamento da variable estudada son moito menos perceptibles a partir da crise que no caso de Cataluña).

\section{CONCLUSIÓNS.}

España e Francia, dúas das principais potencias turísticas a nivel mundial, ostentan cifras moi próximas en canto a chegadas e ingresos por turismo internacional, pero, experimentan notables diferenzas no comportamento e evolución dunha das principais fontes económicas do sector, como é o número de ocupados en turismo. 
Neste senso, a pesar de que tanto a chegada de turistas estranxeiros como o PIB son variables relevantes na xeración de emprego turístico nestes dous países, en España é a primeira a que exerce unha maior influencia sobre o emprego en turismo; mentres que para o caso francés, é o nivel de riqueza xerada.

Estas dúas potencias turísticas, non só diverxen neste aspecto, senón que tamén manifestan unha resposta diferente ante a actual crise en canto á evolución na converxencia/ diverxencia rexional do seu nivel de emprego turístico. Namentres que en España, obsérvase a partir de 2007 un incremento das diverxencias rexionais nesta variable, motivada fundamentalmente, por un proceso de destrución de emprego turístico sofrido máis intensamente por unhas rexións que por outras; en Francia, continouse durante a crise co proceso de converxencia rexional que se viña dando en anos anteriores, grazas á creación de emprego neste sector. Deste xeito, pódese dicir que, a través da análise realizada, o comportamento dos ocupados en turismo en Francia, si responde ao comportamento mencionado pola diversa literatura, á que se fixo mención no epígrafe introdutorio, no senso de que o sector turístico manifesta un mellor comportamento ca outros sectores durante as fases de crise do ciclo económico.

Finalmente, estas disimilitudes no emprego turístico entre estos dous países tamén se reflicten nas súas principais rexións turísticas: Cataluña, para o caso español, e île-deFrance para Francia. Nas dúas, o crecemento do número de ocupados en turismo supera a media nacional, presentando unha maior competitividade cas súas rexións veciñas. Porén, aprécianse diferenzas entre os dous territorios durante a actual etapa de crise, xa que esta tivo unha maior repercusión nos compoñentes do crecemento do emprego turístico no caso de Cataluña que en Île-de-France. Neste último, o comportamento do seu emprego turístico non presenta cambios perceptibles entre o período anterior á crise e a situación actual, caracterizado, fundamentalmente, pola súa especialización e crecemento. A diferenza do caso francés, en Cataluña, a crise provoca unha mellora da súa competitividade xeral en canto a ocupados no sector turístico con respecto ao indicador nacional e ás súas rexións limítrofes. Esta observación permite abrir futuras liñas de investigación que persigan explicar as causas que motivaron este cambio, xa sexan imputables a unha mellora nas políticas de emprego turístico da comunidade catalá, ou a un efecto máis acusado da crise sobre as súas rexións lindeiras, de menor tradición turística, entre outras posibles causas.

\section{REFERENCIAS BIBLIOGRÁFICAS.}

Arias Ramírez, R. y Sánchez Hernández, L. (2010): “Competitividad, especialización y mercado laboral en el cantón de Pérez Zeledón: Un análisis de economía regional”, IICE, 28(1).

Barff, R. A. y Knight III, P.L. (1988): “Dynamic Shift-Share Analysis”, Growth and Change, 19 (2), 1-10.

Casler, S.D. (1989): "A theorical context for shift and share analysis", Regional Studies, $23(1) ; 43-48$.

Chalmers, J.A. y Beckhelm, T.L. (1976): "Shift and share and the theory of industrial location", Regional Studies, 4(1); 15-23.

Direction Générale de la compétitivité de l'industrie et des services (DGCIS): http:// www.dgcis.gouv.fr/ (Consultado el 28 de enero de 2014).

Dunn, E. (1960): "A statistical and analytical technique for regional analysis", Papers of the Regional Science Association, 6, 97-112. 
Eurostat: $\quad$ http:// epp.eurostat.ec.europa.eu/portal/ page/ portal/ eurostat/ home/ (Consultado el 11 de enero de 2014).

Flores Ruiz, D. y Barroso González, M. O. (2010): "Comportamiento del turismo internacional en tiempos de crisis económicas", XII Reunión de Economía Mundial, Santiago de Compostela.

Garrido Yserte, R. (2002): Cambio estructural y desarrollo regional en España, Pirámide, Madrid.

Gerking, S.D. y Barrington, J. (1981): "Are regional share effects constant over time?", Journal of Regional Science, 21; 163-174.

Gujarati, D.N. (2004): Econometría, 4ª edición. McGraw-Hill, México.

Instituto de Estudios Turísticos (IET) (2012): Informe anual 2011. Ministerio de industria, energía y turismo.

Institut National de la Statistique et des Études Économiques (INSEE): http:// www.insee.fr/ fr/themes/ document.asp?reg id=20\&ref id=20231 (Consultado el 4 de enero de 2014).

Instituto Nacional de Estadística (INE): http:/ / www.ine.es/ (Consultado el 12 de enero de 2014).

Knudsen, D.C. y Barf, R. (1991): "Shift-Share Analysis as a Linear Model”, Environment and Planning, 23; 421-431.

Martín Rodríguez, M. (1998): "La economía de las regiones españolas en el largo y muy largo plazo", en Mella Márquez, J.M.: Economía y Política Regional en España ante la Europa del siglo XXI, Akal Textos, Madrid, 129-146.

Massieu, A. (2004): "El sector turístico visto desde la OMT: una reflexión a partir de la coyuntura reciente a nivel mundial", en Uriel, E. y Hernández, R.: Análisis y tendencias del turismo, Pirámide, Madrid, 19-44.

MasterCard Global Destination Cities 2013 Index: http:// newsroom.mastercard.com/ digital-press-kits/mastercard-globaldestination-cities-index-2013/(Consultado el 28 de diciembre de 2013).

Mayor Fernández, M. y López Menéndez, A.J. (2005): “El análisis shift-share: nuevos desarrollos espaciales”, VIII Encuentro de Economía Aplicada, Murcia.

Ministère de l'écologie, du développement durable et de l'énergie: http:// lannuaire.service-public.fr/ services nationaux/administration-centraleou-ministere 172222.html

Ministerio de industria, energía y turismo: http://www.minetur.gob.es/ esES/ Paginas/index.aspx (Consultado el 3 de enero de 2014).

Moreno Gil, S. y Picazo Peral, P. (2012):"Difusión de la investigación científica en revistas de turismo realizada por instituciones españolas", Revista de Análisis Turístico, 14(2); 33-52.

Nazara, S. y Hewings, G.J.D. (2004): "Spatial Structure and Taxonomy of Decomposition in shift-share analysis", Growth and Change, 35(4); 476 - 490.

Nel-lo Andreu, M. y Pérez Albert, Y. (2007): “La política turística en Panamá. Resultados y perspectivas", Cuadernos de Turismo, 20; 199-221.

Organización Mundial del Turismo (OMT) (2013a): "International tourism on the rise boosted by strong performance in Europe", Comunicado de prensa, 17 octubre 2013. 
Organización Mundial del Turismo (OMT) (2013b): Tourism Highlights, 2013 Edition, UNWTO.

Ramajo Hernández, J. y Márquez Paniagua, M.A. (2008): "Componentes espaciales en el modelo shift-share. Una aplicación al caso de las regiones peninsulares españolas", Estadística española, 50 (168); 247-272.

Torres Bernier, E. (1994): "Turismo y desarrollo regional”, Papers de Turisme, 14-15, 95102.

Varisco, C. (2007). "Iniciativas de desarrollo local y fomento del cluster turístico", Aportes y Transferencias, 1, 11, 31:42.

World Travel \& Tourism Council (WTTC): http://www.wttc.org/_Consultado el 13 de enero de 2014).

Revista Galega de Economia at Ideas: http:// https:/ ideas.repec.org/ s/ sdo/ regaec.html

Bulletin and News of Revista Galega de Economía at: http:/ / www.usc.es/ econo/ RGE/ benvidag.htm 